\title{
GEOGRAFIA E LITERATURA (CIÊNCIA E ARTE): PROPOSIÇÕES PARA UM DIÁLOGO
}

- FELIPE MOURA FERNANDES

Resumo: 0 ensaio busca expor referenciais teóricos com 0 intuito de realizar uma pesquisa na área de História do Pensamento Geográfico. Tal pesquisa visa tencionar as fronteiras existentes entre a Arte e Ciência. Para isso, pretende dialogar a Geografia com a Literatura, partindo do pressuposto de que existe um pensamento geográfico na obra de Lima Barreto - tendo como texto âncora 0 romance Triste Fim de Policarpo Quaresma. Em nossa avaliação, o diálogo entre a Arte e a Ciência possui um lugar central no atual cenário intelectual, onde as fronteiras das ciências estão em cheque e as interdisciplinaridades se multiplicam. Dessa forma, nosso trabalho também pretende demonstrar como a ficção pode se tornar uma valiosa fonte para a realização de pesquisas no campo das ciências sociais no geral e da Geografia em particular.

Palavras-chave: geografia ; literatura ; pensamento geográfico ; política ; linguagem

Introdução

Esse trabalho faz parte de um projeto de pesquisa - em seu estágio inicial - que versa sobre a relação entre a geografia (ciência) e a literatura (arte) ${ }^{1}$. A tese tem como pressuposto a possibilidade de identificar e analisar um projeto de Brasil territorialmente pensado na literatura produzida pelo escritor Afonso Henriques de Lima Barreto (1881-1922). Nossa análise terá como foco o romance Triste Fim de Policarpo Quaresma - publicado como livro em 1915. No entanto, o cruzamento do espaço romanesco com textos pertencentes a outros gêneros literários, tais como os contos, será de extrema importância para o aprofundamento de nossas análises. A afirmação da presença de um pensamento geográfico ${ }^{2} \mathrm{em}$ Triste Fim de Policarpo Quaresma é acompanhada da necessidade de identificar a linguagem ${ }^{3}$ pelo ESPAÇO E CULTURA, UERJ, RJ, N. 33, P.167-176, JAN./JUN. DE 2013

http://www.e-publicacoes.uerj.br/index.php/espacoecultura/ 
qual ele é expresso e a estratégia narrativa ou o posicionamento político ${ }^{4}$ discursivo em que ele está inserido. Em linhas gerais, esses seriam os três principais objetivos do trabalho: i) identificar e analisar a presença do pensamento geográfico na obra literária em tela; ii) pontuar a linguagem usada para expressar o pensamento geográfico em questão; e iii) associar o pensamento e sua linguagem a um posicionamento político e discursivo.

$\mathrm{Na}$ montagem do projeto, sentimos a necessidade de buscar um referencial teóricometodológico que nos inserisse no debate sobre o Brasil através da cultura política. Nesse sentido, vale dizer que também é nosso objetivo demonstrar a presença de um pensamento geográfico na(s) ideia(s) de Brasil formuladas na Primeira República - o recorte temporal de nossa pesquisa. Para isso, pretendemos relacionar três eixos teóricos que devem ser apurados ao longo de seu desenvolvimento, sendo eles: i) posicionamento historiográfico nesse ponto, situamos nosso trabalho em relação às pesquisas realizadas na área de história do pensamento geográfico no Brasil; ii) teoria literária - apresenta uma análise sobre o nosso autor (Lima Barreto) a partir de alguns referenciais da teoria crítica; e iii) balanço historiográfico - como os geógrafos ao longo da história da geografia (ciência) vêm pontuando a relação entre geografia e literatura. Vale ressaltar que há inúmeras relações entre o que estamos chamando de eixos teóricos, brevemente explicitados a seguir.
Faremos uma exposição sobre os apontamentos teóricos que temos desenvolvido e serviram de base para a elaboração do projeto.

\section{Posicionamento Historiográfico}

Estamos em acordo com o posicionamento historiográfico que afirma haver um pensamento geográfico brasileiro antes das instituições e discursos que fundam a geografia como ciência moderna. Vale destacar que as universidades que estabeleceram cursos de geografia só vieram a ser fundadas em 1934 e 1935, na Universidade de São Paulo e Universidade do Distrito Federal, respectivamente.

Nosso interesse maior versa sobre a relação intrínseca entre as representações espaciais e as concepções de política/república de Lima Barreto e como esse mesmo autor as desenvolve através de uma linguagem diferenciada da literatura dominante em sua época - Primeira República (1889-1930). A partir disso, não referendamos o posicionamento historiográfico que afirma o estabelecimento de um pensamento geográfico brasileiro apenas a partir da fundação das universidades. Entendemos que não abandonar essa premissa seria afirmar a necessidade da autorização estrangeira (europeia/francesa/colonialista) para afirmar a existência de um pensamento geográfico no Brasil através das universidades.

Souza-Neto (2001, p. 129) afirma que apenas a partir da década de 1980 "(...) se 
começou a falar em pensamento geográfico no Brasil, como forma de driblar essa tradição memorialística para estabelecer uma leitura da história social das idéias geográficas". Assim, temos o objetivo de contribuir com o pensamento geográfico brasileiro, estabelecendo o diálogo entre a ciência geográfica e a literatura. Com base em Moraes (1988, p. 32), entendemos por pensamento geográfico "um conjunto de discursos a respeito do espaço que substantivam concepções que uma dada sociedade, num momento determinado, possui acerca do seu meio (desde o local ao planetário) e das relações com ele estabelecidas". Além disso, Moraes (1988) indica a presença do pensamento geográfico na literatura: "Eles emergem em diferentes contextos discursivos, na imprensa, na literatura, no pensamento político, na estatística, na pesquisa científica, etc".

Julgamos necessário acompanhar uma reflexão sobre a obra de Lima Barreto a partir da crítica literária. Entendemos que essas reflexões ajudam a situar o escritor, no espectro mais amplo da literatura brasileira, em seu devido contexto político. A crítica literária também contribui para entendermos as especificidades da obra de Lima Barreto além de uma perspectiva memorialista.

\section{Crítica Literária}

Carlos Nelson Coutinho (1990), em seu ensaio, faz uma interessante análise de Lima Barreto, centrada nos romances Vida e morte de
M. J. Gonzaga de Sá, Recordações do Escrivão Isaías Caminha e aquele que é considerado pelo nosso crítico o romance auge de Lima Barreto: $O$ triste fim de Policarpo Quaresma. Para desenvolver sua análise, Coutinho (1990, 101 104) apresentou alguns conceitos, sendo esses: "revolução passiva" de Gramsci e a "via prussiana" de Lênin. Além disso, associa tais conceitos a uma ideia desenvolvida por Tomas Mann, o "intimismo à sombra do poder" 5 . Dessas três unidades de pensamento, a "via prussiana" se torna chave. A ideia de "revolução passiva" fica como uma aproximação da primeira e papel parecido cumpre o "intimismo à sombra do poder". Essas ideias são utilizadas para caracterizar um posicionamento de "submissão" da intelectualidade brasileira em relação ao Estado, presente nas diferentes perspectivas literárias durante a Primeira República.

Dessa forma, entendemos que a "via prussiana" e o "intimismo à sombra do poder", além de revelar a submissão dos intelectuais brasileiros ao Estado, também caracterizam uma postura de distanciamento em relação às classes populares e, consequentemente, à cultura popular.

No desenvolver de sua análise, Coutinho (1990) demonstra como a perspectiva estético-narrativa (exigida pelo romance) e o posicionamento ideológico de Lima Barreto avançam na elaboração dos seus três principais romances. Dessa forma, percebemos como o realismo de Lima Barreto rompe com a perspectiva de desenvolvimento caracterizado a partir da "via prussiana". Encontramos, nas 
opções estético-literárias de Lima Barreto, a necessidade de um mergulho nas classes populares, na sua cultura, no seu ethos.

Coutinho ainda destaca que essa ruptura não foi alcançada pelo Romantismo, nem pelo Naturalismo brasileiros. Sequer Machado de Assis foi capaz de romper com o "intimismo à sombra do poder". Sobre as questões relacionadas ao Romantismo e o Naturalismo, Coutinho (1990, p. 107-108) destaca que "O romantismo (...) busca na evasão subjetivista diante do prosaísmo desumanizante da realidade concreta o seu específico material poético, (...) o naturalismo, (...), recusando o subjetivismo dessa evasão, limita-se a descrever a estagnação e a considerála como algo 'fatal' e imutável". Coutinho (1990, p. 113). No que diz respeito a Machado de Assis: "Aquela excepcionalidade que caracteriza o realismo brasileiro, aliada às conciliações exteriores e a essa característica ideológico-estilística de sua obra, impediram que Machado de Assis exercesse uma influência positiva imediata no sentido de dissolver a continuidade das tendências 'intimistas' 6"'

Em nossa compreensão, o "subjetivismo" do Romantismo, a quase determinação do meio presente no Naturalismo e o "intimismo" e a "serenidade" machadianos - salvo as devidas especificidades e potencial crítico - não conseguiram romper com o caráter aristocrático da literatura brasileira. Essas literaturas não demonstram uma predileção pelas classes populares, pelos "humildes" e/ou pelos "humilhados". Essas tendências literárias se aproximam da ideia do "intimismo à sombra do poder" ou da perspectiva de desenvolvimento caracterizado pela "via prussiana" e é justamente essa característica de nossa literatura que será combatida por Lima Barreto, na sua predileção "pelos humildes e humilhados". De acordo com Coutinho (1990, p. 116): “(..) contra a herança imediata de Machado, Lima Barreto expressa sua categórica rejeição do 'intimismo' e, (...), lança as bases de sua luta - solitária na época pela retomada da linha realista no que ela tinha de essencial".

Lima Barreto, ao longo da sua obra, faz uma crítica intensa à Primeira República portadora dos ideais de modernização. Nesse sentido, o autor possui alguns posicionamentos passadistas, por perceber que a monarquia se estabeleceu perante o povo com mais vigor. Nas palavras de Coutinho (1990, p. 118): "O país ingressava na era capitalista (que já atingia no plano mundial a fase imperialista) sem ter resolvido os impasses históricos decorrentes da 'via prussiana'. Com isso, dissolver-se-iam inteiramente os aparentes traços de 'estabilidade’ da época imperial (...)".

\section{Balanço Historiográfico: Geografia e Literatura}

Em acordo com o levantamento historiográfico feito por Marc Brosseau (2007, p. 17), entendemos que o "interesse dos geógrafos pela literatura não é novo". Esse autor destaca que Paul Vidal de La Blache aponta para uma geografia existente na obra Odisseia, em 
um artigo publicado nos Annales de Geografia em 1904. Também é importante notificar que Humboldt - autor base para o desenvolvimento do pensamento geográfico moderno ${ }^{7}-$ dedicou dois capítulos do Cosmos à Literatura e à Pintura.

No entanto, devemos considerar que a relação entre a Geografia e a Literatura ficou quase totalmente adormecida até a década de 1970. De acordo com Brosseau (2007, p. 18), antes dessa década, tal relação esteve voltada para utilização do "romance como complemento das análises regionais". Os romances, e por consequência a literatura, "não eram considerados suscetíveis de construir bases sólidas para uma geografia científica e rigorosa" (2007, p. 19). Dessa forma, entendemos como os ideais associados à construção de uma cientificidade, à delimitação da geografia como campo científico, não permitiram uma ampla difusão da relação geografia-literatura ou ciência-arte.

Dessa forma, a partir da década de 1970, surgiu uma perspectiva de geografia crítica - associada ao marxismo - e uma concepção de geografia humanista - "evocando de maneira mais ou menos direta a fenomenologia (...)" (BROSSEAU, 2007, p. 19). É interessante notar que ambas expressavam uma reação à geografia quantitativa. Mas foi a partir do desenvolvimento das ideias associadas ao campo humanista que a relação entre a geografia e a literatura ganhou um novo fôlego. De acordo com Brosseau (2007, p.20-21), esse primeiro momento da relação entre geografia e literatura se desenvolveu de forma mais intensa no pensamento geográfico anglo-saxão que no pensamento geográfico francês. Essa retomada temática parece ficar explícita quando Brosseau cita a realização de alguns eventos, como o Encontro da União Geográfica Internacional (UGI), realizado em 1972, no qual havia uma "sessão sobre a utilização dos romances regionais para o ensino da disciplina"; em 1974, a Associação dos Geógrafos Americanos "teve lugar uma reunião sobre as paisagens na literatura"; "em 1979, o Instituto dos Geógrafos Britânicos dedicou um dos seus encontros anuais às relações gerais entre Geografia e Literatura" (BROSSEAU, 2007, p. 20).

A partir disso, podemos dizer que as relações entre a geografia e a literatura assumem três perfis, de acordo com o balanço teórico e historiográfico proposto por Brosseau (2007): primeiramente, a literatura aparece como complemento de uma geografia regional; em um segundo momento, como transcrição da experiência dos lugares; e em um terceiro momento, como crítica social da realidade.

O primeiro perfil, brevemente explicitado anteriormente, esteve pautado nas tentativas de fazer da literatura um complemento da geografia regional. Podemos indicar a existência de uma preocupação rígida com o método e o comprometimento do conhecimento científico com a construção da verdade. De acordo com Brosseau (2007, p.24), algumas questões de cunho metodológico assumiam determinada importância na tentativa 
de averiguar a veracidade das informações que o romance trazia à tona, tais como: "ver se o autor viveu nos lugares que descreve"; realizar "leituras comparativas" de diferentes autores que falem do mesmo tema em uma determinada época" (BROSSEAU, 2007, p. 25). Essas questões tinham como propósito "avaliar a capacidade documental do romance" (idem, p. 26). Ainda vale destacar que "o romance realista do século XIX" foi o "favorecido na sua capacidade de relação com a geografia". E esse favorecimento está associado ao "controle mais fácil de seus elementos considerados puramente 'subjetivos'" (ibidem, p. 28).

O segundo perfil está associado à geografia humanista e procura "situar o sujeito no centro das preocupações dos geógrafos em suas reflexões sobre os lugares" (BROSSEAU, 2007, p. 29). Para isso, a geografia que vinha se desenvolvendo como a "ciência do espaço" ganha uma nova proposição como "ciência dos lugares para o homem (TUAN, 1974; BUTTIMER e SEAMON, 1980)" (apud BROSSEAU, 2007, p. 28-9). Nesse momento, com objetivo de trazer o sujeito para o centro do debate, esse perfil trabalhou a partir de noções como: "valores, representações, intenções, subjetividade, identidade, enraizamento, experiência concreta e percepção" (idem). Na avaliação de Marc Brosseau (2007), essa perspectiva "construiu seu credo ao redor da noção sense of place". Em nosso entendimento a partir da perspectiva humanista da relação geografia e literatura, o objetivo principal foi fazer da literatura um objeto privilegiado onde os geógrafos pudessem trabalhar o confronto entre objetividade e subjetividade. Nas palavras de Brosseau (2007, p. 31), "(...) os geógrafos humanistas privilegiam o romance na medida em que lhes parece propiciar a ocasião ideal de encontro entre o mundo objetivo e o mundo da subjetividade". Nesse sentido, o romance viria ampliar as teses ao redor das identidades espaciais. Dessa forma, consideramos que esse perfil não privilegiou as representações do mundo exterior a partir de uma perspectiva literal, da tentativa de mostrar as coisas tal como elas são - como parece ficar explícito no perfil anterior, associado à geografia regional francesa. Esse grupo vai privilegiar uma apreensão dos lugares, tendo como base uma leitura de sua apreensão subjetiva.

Brosseau (2007, p. 35-6), dialogando com a perspectiva humanista em seus primeiros estágios, propõe questões importantes: "Não seria legítimo indagar se existe uma diferença entre as palavras e as coisas, entre a nossa percepção destas e aquilo que conseguimos falar delas". Com base em Merleau-Ponty, prossegue em suas questões: "Convém somente se perguntar se a experiência, desde o momento que é assumida pela linguagem, ainda é tomada na sua imediaticidade". Sem a intenção de ser conclusivo, com esse debate, o autor coloca uma questão importante para nós: "gostaria de tentar compreender por que a maior parte dos geógrafos humanistas preferiu situar a relação da geografia e da literatura no terreno da consciência e do imaginário, deixando de 
considerar as mediações complexas que o discurso e as escrituras fazem intervir" (BROSSEAU, 2007, p. 43).

Esse questionamento é de grande valor porque entendemos que é a partir das "mediações complexas" entre o "discurso" e a "escritura" que o elemento político ganha importância. No entanto, parece que a preocupação com a política ou com os elementos que envolvem a política não eram de grande relevância para a perspectiva humanista. Em sua tentativa de trazer o sujeito para o centro do debate, fica a sensação de que esse perfil deixou algumas lacunas. Não desconsiderando os avanços significativos para o pensamento geográfico promovido por essa perspectiva, entendemos que, de um lado, o sujeito estava reduzido a dados quantificáveis (New Geography), e, de outro, estava associado a uma produção burguesa da sociedade capitalista (Geografia Radical ou Crítica).

O terceiro perfil identificado a partir do levantamento historiográfico de Brosseau (2007, p. 46) parte da utilização da literatura como uma forma de "crítica da realidade ou ideologia dominante". Essa perspectiva, segundo o autor, pretende buscar na relação geografia-literatura formas que possam potencializar a construção de um futuro com "uma justiça social mais ampla". Além disso, "os estudos de inspirações marxistas também procuraram na literatura um meio de demonstrar aquilo que a realidade poderia ou deveria ser".

Ainda com base nas observações de Brosseau (2007, p. 44), destacamos que a geografia humanista acabou produzindo "uma celebração excessiva do papel sujeito", onde o "contexto, coerção e estratificação social foram pouco consideradas". Enfim, com base nesse mesmo autor, afirmamos que a perspectiva humanista não desenvolveu uma reflexão que leve em consideração o papel do sujeito sem ignorar os contextos aos quais os textos estão inseridos.

Entendemos que tais preocupações que procuram problematizar as "mediações" entre "discurso e escritura" estão em consonância com a perspectiva que valoriza o elemento político - associado às necessidades de contextualização dos textos.

A partir desse levantamento teórico, compreendemos como necessidade do tempo presente a retomada da discussão acerca do sujeito e de suas possíveis representações. No entanto, não entendemos que a aproximação do sujeito para o centro do debate elimina as relações contextuais mais amplas associadas a elementos teóricos e políticos. Temos por princípio a ideia de que de, em todo texto, o leitor tira melhor pretexto se compreender seu contexto, mas, para isso, a consideração do sujeito é algo fundamental.

Outra questão metodológica desenvolvida por Brosseau (2007, p. 81-82) versa sobre a forma como encaramos a relação sujeito-objeto (pesquisador-pesquisa) ao afirmar que: "O interesse por uma relação dialógica reside na sua vontade de reconhecer o outro enquanto outro, isto é, na recusa de transformálo em objeto, de 'homologá-lo'. No interior de 
uma relação como essa, o outro permanece sujeito". Ao afirmar o diálogo como uma relação onde "o outro" deve ser considerado "sujeito", o autor contribui para pensarmos a nossa relação com o texto literário. Ou seja, de acordo com Marc Brosseau (2007), a Geografia Regional, a Geografia Humanista e a Geografia Radical ou Crítica delegaram - na maioria dos trabalhos - o papel de "objeto" de pesquisa para a Literatura e posicionou o sujeito pesquisador do lado oposto. A pior consequência dessa postura metodológica é o desejo de ver no texto

\section{NOTAS}

\footnotetext{
1 Doutorando do Programa de Pós-Graduação em Geografia Humana da Universidade de São Paulo, sob a orientação do Prof ${ }^{\circ}$ Dr. Elvio R. Martins.

2 Nosso entendimento sobre o "pensamento geográfico" está baseado em A. C. R. de Moraes, em seu livro Ideologias Geográficas (1988), e no texto de Manoel Fernandes Souza Neto, Geografia nos Trópicos: história de uma jangada de pedra (2001).

${ }^{3}$ A discussão sobre linguagem é diversa e passa por diversos campos do conhecimento, tais como a filosofia, a linguística, a filosofia da linguagem, as ciências da comunicação, etc. Inicialmente, fizemos uso do verbete de José Ferrater Mora (2001, p. 422) encontrado em seu Dicionário de Filosofia. Outras referências têm sido buscadas nos livros Marxismo e Filosofia da Linguagem, de Mikhail Bakthin (2010), e Ideologia e Linguagem, de José Luis Fiorin.

${ }^{4}$ Hanna Arendt (2004) traz uma concepção de política que tem nos orientado. Essa autora afirma que a base da política é a diversidade (p. 21) e o sentido da política é a liberdade (p. 39). A não oposição entre liberdade e diferença nos desperta interesse.

${ }^{5}$ De acordo com o próprio Coutinho (1990, p.103): "O termo aparece no ensaio manniano Grandeza e sofrimento de Richard Wagner, citado e comentado por Geörgy Lukács, Thomas Mann, Paris: Maspero, 1967, p.162. Este conceito foi amplamente utilizado por Lukács em suas análises literárias (sempre em relação ao conceito da "via prussiana"), servindo-lhe como fio condutor na compreensão de muitos problemas da história literária alemã e húngara. No presente ensaio, valho-me dessas ideias e sugestões lukacsianas, na tentativa de esclarecer problemas específicos da literatura brasileira".

${ }^{6} \mathrm{Na}$ continuidade da citação, Coutinho (1990, p.113) acrescenta: "Reside aqui a razão profunda dos ataques de Lima Barreto, ao longo de sua vida, não cessou de dirigir a Machado de Assis."

${ }^{7}$ Essa afirmação tem como base as reflexões de Ruy Moreira, na seção intitulada de "Geografia Clássica", em Pensamento Geográfico Brasileiro vol. I.
}

literário somente as suas necessidades de pesquisa. Quando nos dirigimos para o romance com uma ideia muito fechada do que queremos ver, acabamos por amordaçar o "outro" - o texto literário. Assim, pretendemos estabelecer uma relação de diálogo com os textos nos quais sujeito e objeto da pesquisa - em suas formas clássicas - possuem uma relação contínua. Temos como princípio a ideia de que o objeto só é possível de ser alcançado a partir da subjetivação do sujeito, mas, ao fazê-lo, o sujeito torna-se objeto de si mesmo.

\section{REFERÊNCIAS} BIBLIOGRÁFICAS

BARRETO, Lima. Triste Fim de Policarpo Quaresma. São Paulo: Ed. Penguim \& Cia das Letras, 2011.

BROSSEAU, Marc. Geografia e Literatura. IN: CORRÊA, Roberto Lobato; ROSENDAHL, Zeny (org.). Literatura, Música e Espaço. Rio de Janeiro: EDUERJ, 2007.

O Romance: outro sujeito para a Geografia. IN: CORREAA, Roberto Lobato; ROSENDAHL, Zeny (org.). Literatura, Música e Espaço. Rio de Janeiro: EDUERJ, 2007.

COUTINHO, Carlos N. Cultura e Sociedade no Brasil: ensaio sobre idéias e formas. Belo Horizonte: Oficina de Livros, 1990.

HANNA, Arendt. O que é política? Fragmentos das obras póstumas compilados por Ursula Ludz. Rio de Janeiro: Ed. Bertrand Brasil, 2004

MORAES, Antonio C. R. de. Geografia Histórica do Brasil. São Paulo: Anna Blume, 2009. 2008.

Território e História do Brasil. São Paulo: Anna Blume,

Ideologias Geográficas: espaço, cultura e política no Brasil. São Paulo: Ed. Hucitec, 1988

MOREIRA, Ruy. O Pensamento Geográfico Brasileiro: as matrizes clássicas originárias. São Paulo: Contexto: 2008.

PIRES, Murilo J de S; RAMOS, Pedro. O termo modernização conservadora: sua origem e utilização no Brasil In: Revista Econômica do Nordeste, vol. 40, nº 3, julho-setembro de 2009.

SOUZA-NETO. Manoel F. Geografia nos trópicos: história de uma jangada de pedra? São Paulo: Terra Livre, n.17, p.119-138, 2001. 
MY PURPOSE IS TO EXPOSE THEORETICAL FRAMEWORKS IN ORDER TO CONDUCT RESEARCH ON THE HISTORY OF GEOGRAPHICAL THOUGHT. THIS RESEARCH AIMS TO INTEND THE BOUNDARIES BETWEEN ART AND SCIENCE. FOR THIS, WE INTEND TO ENGAGE WITH THE GEOGRAPHY LITERATURE, ASSUMING THAT THERE IS A GEOGRAPHICAL THOUGHT IN THE WORK OF LIMA BARRETO - HAVING AS ANCHOR TEXT THE NOVEL O TRISTE FIM DE POLICARPO QUARESMA. IN OUR ASSESSMENT, THE DIALOGUE BETWEEN ART AND SCIENCE hAS A CENTRAL PLACE IN THE CURRENT INTELLECTUAL LANDSCAPE, WHERE THE BOUNDARIES OF SCIENCE ARE IN CHECK AND INTERDISCIPLINARY IS A COMMONPLACE. THUS, OUR WORK ALSO AIMS TO DEMONSTRATE HOW FICTION CAN BECOME A VALUABLE SOURCE FOR CONDUCTING RESEARCH IN THE FIELD OF SOCIAL SCIENCES IN GENERAL AND GEOGRAPHY IN PARTICULAR.

KEYWORDS: GEOGRAPHY - LITERATURE - GEOGRAPHICAL THOUGHT - POLITICAL - LANGUAGE

GEOGRAPHIE ET LA LITTERATURE (SCIENCE ET ART): PROPOSITIONS POUR LE DIALOGUE

RÉSUMÉ: MON BUT EST D'EXPOSER LES CADRES THEORIQUES AFIN DE MENER DES RECHERCHES DANS LE DOMAINE DE L'HISTOIRE DE LA PENSEE GEOGRAPHIQUE. CETtE RECHERCHE VISE A L'INTENTION DES FRONTIERES ENTRE ART ET SCIENCE. POUR CELA, NOUS AVONS L'INTENTION DE COLLABORER AVEC LA LITTERATURE DE LA GEOGRAPHIE, EN SUPPOSANT QU'IL EXISTE UNE PENSEE GEOGRAPHIQUE DANS LE TRAVAIL DE LIMA BARRETO - AYANT COMME TEXTE D'ANCRE LE ROMAN TRISTE FIN DE POLICARPO QUARESMA. DANS NOTRE EVALUATION, LE DIALOGUE ENTRE L'ART ET LA SCIENCE OCCUPE UNE PLACE CENTRALE DANS LE PAYSAGE INTELLECTUEL ACTUEL, OU LES FRONTIERES DE LA SCIENCE SONT EN ECHEC ET INTERDISCIPLINARIDADES SE MULTIPLIENT. AINSI, NOTRE TRAVAIL VISE EGALEMENT A DEMONTRER COMMENT LA FICTION PEUT DEVENIR UNE SOURCE PRECIEUSE POUR MENER DES RECHERCHES DANS LE DOMAINE DES SCIENCES SOCIALES EN GENERAL ET DE LA GEOGRAPHIE EN PARTICULIER.

MOTS-CLES: GEOGRAPHIE - LITTERATURE - PENSEE GEOGRAPHIQUE - POLITIQUE - LANGUE 
ESPAÇO E CULTURA, UERJ, RJ, N. 33, P.167-176, JAN./JUN. DE 2013 http://www.e-publicacoes.uerj.br/index.php/espacoecultura/ 